\title{
Cognitive deficit and depressive symptoms in a community group of elderly people: a preliminary study*
}

\author{
Claudia Siberman, Carolina Souza, Fábio Wihems, Leticia Kipper, Vivian Wu, \\ Cesar Diogo, Marcelo Schmitz, Airton Stein and Márcia Chaves
}

Hospital Nossa Senhora da Conceiçäo - Porto Alegre, RS - Brasil (C.S., A.S.), Faculdade de Medicina da Universidade Federal do Rio Grande do Su - Porto Alegre, RS - Brasil (C.S., F.W., L.K., V.W., C.D., M.S., M.C.)

\begin{abstract}
Since the number and proportion of old people increases worldwide, health protessionals and systems should be made aware and prepared to deal with their problems. Cognitive deficit and symptoms of depression are commom among the elderly, and may occur in relation to various risk factors such as health conditions and psychosocial variables. In order to study cognitive deficit and the presence of signs and symptoms of depression, 62 elderly community subjects enrolled at a Community Health Unit in Porto Alegre, southern Brazil, were interviewed. They were evaluated by means of the Mini Mental State Exam, the Montgomery-Asberg Depression rating scale, and a questionnaire on health conditions, living arrangements and social variables. Higher levels of symptoms of depression were observed among subjects exposed to major risk factors for cerebrovascular diseases (diabetes and coronary disease), while impaired cognitive performance was seen among individuals who could not count on the presence of a confidant (social network variable). The results suggest that the early identification of major risk groups among old people can heip to prevent institutionalization and keep individuals in the community.
\end{abstract}

Depression, epidemiology. Cognitive disorders, epidemiology. Aged.

\section{Introduction}

The number and proportion of older people are increasing throughout the world and call for a special awareness on the part of health systems. In the 30 years from 1970 to 2000 , the world population will increase by $70 \%$, whereas the proportion of individuals over 60 years old will increase by $91 \%$. For people over the age of 80 , this increase will be of around $119 \%^{30.40}$. In Brazil, individuals over 65 years number approximately 7 million or $4.5 \%^{16}$. By the year 2000 this proportion will be of aproximately $8 \%$ and the Brazilian elderly population will be the seventh largest in the world ${ }^{8}$.

Depression and cognitive impairment are very frequent among the neuropsychiatric disorders observed in the elderly. In European countries and the USA, 10 to $15 \%$ of individuals over 65 years old present some cognitive deficit and 5\% present demential.24. In a study carried out in Rio de Janeiro, Brazil concerning the prevalence of organic brain syndrome the results varied from 5.9 to $29.7 \%$ in three different districts ${ }^{43}$. Almeida Filho ${ }^{2}$ showed, in the state of Bahia, $6.8 \%$ of cases of dementia and $36.4 \%$ of some mental disorder syndrome. By the use of the Face-Hand test $5.5 \%$ of organic brain syndrome was identified among subjects over the age of 65 in S. Paulo ${ }^{6}$. In another study in S. Paulo ${ }^{13}$, Brazil, $25 \%$ of the elderly were found to present some psychiatric disorder.

The prevalence of depressive symptoms among elderly members of the community is of $15 \%$, and severe depressive syndrome is found in around $4 \% 5$. Variances may be a product of many different exposures to risk factors, such as cardiovascular diseases and environmental, genetic and social variables.

\footnotetext{
* Supported by CNPq (Conselho Nacional de Desenvolvimento Cientifico e Tecnologico).

Reprints: Márcia L.F. Chaves - Serviço de Neurologia - Hospital de Clínicas de Porto Alegre - Rua Ramiro Barcelos, 2450-Sala 2040 - 90035-003 - Porto Alegre, RS - Brasil. Fax:(051) 226.4684
}

Received in 5.9.1994. Review in 28.7.1995. Approved in 2.10.1995. 
The social and psychological universes in which the subject is involved seem to play an important role in determining the quality of life. Low institutionalization and mortality rates are related to better quality of life during older age. Recent studies have shown an association of certain social network variables (i.e., "social activities", "visits or talks with friends or relatives") with institutionalization and/or mortality of elderly people ${ }^{3.16 .34,35,38}$. Those elderly people who participated in some kind of social activity and who visited or talked with friends or relatives decreased their risk of mortality by almost one-half, whereas living alone increased the likelihood of institutionalization. Furthermore, public and private expenses on the part of health services were also thus diminished ${ }^{38}$.

The phrase "social network" refers to roles and connections that link individuals in terms of kinship, friendship or acquaintanceship (spouse, relatives, close friends or neighbors) ${ }^{25}$. These social connections can be classified by their structure (size, intensity or frequency). It can be seen as the structure by which social support is provided. Social support measures the functional content of social relations expressed by sources and help provided for a specific individual by another ${ }^{10}$.

Citizens of developed countries have been experiencing an average increase in age as social and health conditions have been improving. Developing countries such as Brazil present basic health and social problems as the population gets older. The question as to how these conditions may influence the prevalence of problems such as depression and cognitive disorders is still unknown. Since depression and cognitive problems among elderly people require appropriate preparation by the health system for their diagnosis and management, the knowledge of their prevalence is important for the planning of a Community Health Service for aging populations.

The objectives of the present study were: 1 , to determine the frequency of cognitive deficit and signs and symptoms of depression in elderly persons who were enrolled in the Outpatient Unit of the Community Health Service of a Hospital; 2, to define some socio-demographic characteristics and identify the social network variables of this group.

\section{Subjects and Methods}

\section{Subjects}

This study has been developed as a joint venture between the Dementia Program of the
Neurology Service of a Hospital and the Outpatient Unit of the Community Health Service of the another Hospital of the city of Porto Alegre, in the southern Brazil.

This Unit was chosen because it takes general care of outpatients from an area with well defined geographical limits, and provides health assistance and education for a population of 30,000 inhabitants. It is located in a northern lower middle class area of Porto Alegre, and has a team composed of 10 general practitioners, 3 medical residents and 2 nurses.

Subjects were selected by systematic sampling of the register of subjects, based on the general prevalence of depression and cognitive deficit $(10 \%)$, with alpha and beta values of $5 \%$ and $10 \%$, respectively. The estimated sample size was of 119 individuals of over 60 years of age.

Every one of the 119 individuals were sought out in their respective places of residence by interviewers, but most of them were not located because the addreses given were incorrect. In these cases and when nobody was found at home the subjects were replaced (after three visits at different times).

The final sample consisted of 62 individuals who were visited at home by research assistants.

\section{Instruments}

The following instruments were applied during the visit:

A. Questionnaire on health and social conditions $^{37}$. This is composed of 42 questions about social (housing, living arrangements etc.), economic and health conditions.

B. Mini Mental State Exam, ${ }^{9.1}$. This is a widely used test composed of five major cognitive items: orientation, registration, attention-calculation, recall, and language. Results are obtained in scores and may vary from 0 to 30 . The higher the score the better the performance.

C. Montgomery-Asberg Depression Rating Scale ${ }^{12.26}$. This scale is comprised of 10 categories of symptoms. Scores are given for individual questions (0-6) and may vary from 0 to 60 . Higher scores express greater presence of symptoms of depression.

Previous validations have been presented for all three instruments for Brazilian samples, as well as translations and re-translations for studies in Portuguese ${ }^{9.12 .37}$. 
The cutoff points for detection of cognitive problems by the Mini Mental State Exam were 24 for literate individuals and 17 for illiterates ${ }^{9.13 .29}$. Symptoms of depression were identified as present by the application of the cutoff point of 10 on the Montgomery-Asberg Depression Rating Scale ${ }^{13.23}$,

The interviewers were 6 undergraduate medical students, who received a 2-week training for the application of the Mini Mental State Exam, the Montgomery-Asberg Depression Rating Scale and the questionnaire on health and social conditions. After the training period, a test of agreement among them was carried out ${ }^{14}$. For this survey, $90 \%$ of agreement was accepted as demonstrating the readiness of the interviewers for field data collection. Quality control was carried out by testing $20 \%$ of cases at random.

\section{Statistical Analysis}

The statistical analysis was made by the use of descriptive statistics, by the Mann-Whitney U test, by the Mantael-Hanszel Chi-square test for associations between categories, and by Pearson's (r) correlation coefficient ${ }^{14}$.

\section{Results}

Results are presented in Tables 1 to 4.

Demographic distribution of the sample is presented in Table 1. Frequencies by sex showed a greater number of women in this age group. The presence of cognitive deficit ( $29 \%)$, depressive symptoms $(30 \%)$ and chronic diseases $(84 \%)$ is very high among this group. Chronic diseases were: obstructive lung disease, heart and coronary

Table 1 - Characteristics of the group studied.

\begin{tabular}{ll}
\hline Variable & Frequency \\
\cline { 2 - 2 } Sex Male & \\
$\quad$ Female & $37 \%$ \\
Age & $63 \%$ \\
Schooling & $70(60-80)$ a \\
Cognitive Deficit & $05(0-16)$ a \\
Depressive Symptoms & $29 \%$ \\
Chronic Disease & $30 \%$ \\
Family Income (person with higher income) & $84 \%$ \\
1 MW & $37 \%$ b \\
$2-3$ MW & $30 \%$ \\
3-21 NW & $33 \%$ \\
Retirement & $82 \%$ \\
\hline
\end{tabular}

a - mean age in years (range) $b-M W=$ minimum wage diseases, gastrointestinal and rheumatic disorders. Stroke was not observed among the subjects.

The income level of the families was classified in three categories (up to 1 legal minimum wage; 2 to 3 legal minimum wages; and 3 to 21 legal minimum wages). The last category includes a higher range of incomes because frequencies of values over 5 were too small to allow different groupings. This reflects the low socio-economic characteristics of the area. Retirement rate was $82 \%$, which includes almost the whole sample.

Illiteracy rate was $15 \%(n=9)$ and the frequency of cognitive deficit was $44 \%(n=4)$, which was not different from that of the better educated group $(\mathrm{n}=14,26 \%)$ (odds ratio $=1.13$; confidence inter$\mathrm{val}=0.20-5.91$; Fisher's exact test).

Conditions of the social network are presented in Table 2. Almost half of the individuals still have a companion, which has been demonstrated to be a protective factor as regards institutionalization and mortality ${ }^{38}$. Other important variables (potential protective factors) are the existence of a "confidant (e)" (somebody in whom individuals can trust and with whom they can share their problems), the maintenance of regular contacts with the confidant(e), their ability to feel at ease with this person and meet him/her easily.

Table 2 - Social network characteristics of the group studied.

\begin{tabular}{ll}
\hline Variable & $\%$ \\
\hline Living arrangement & \\
With spouse & 58 \\
& \\
Children alive (1-2) & 55 \\
Sibling alive (2-3) & 35 \\
Parent alive & 11 \\
Presence of confidant (e) & 93 \\
Meeting with confidant (e) & \\
>1 per week & 76 \\
Confidant (e) & 89 \\
Talks to confidant (e) about problems & 55 \\
Feels at ease in talking with confidant (e) & 78 \\
Understanding confidant (e) & 77 \\
Confidant (e) exchanges problems & 66 \\
Confidant (e) is important & 89 \\
Confidant (e) is close & 87 \\
Somebody helps when ill & 84 \\
\hline
\end{tabular}

Table 3 shows the cognitive function and levels of signs and symptoms of depression in the sample, stratified by chronic disease, sex. age, presence of a confidant(e), and the ability to feel at ease with this person.

The Mini Mental and Montgomery-Asberg scores were tested for the presence of chronic dis- 
Table 3 - Mini Mental and Montgomery-Asberg scores (median and range).

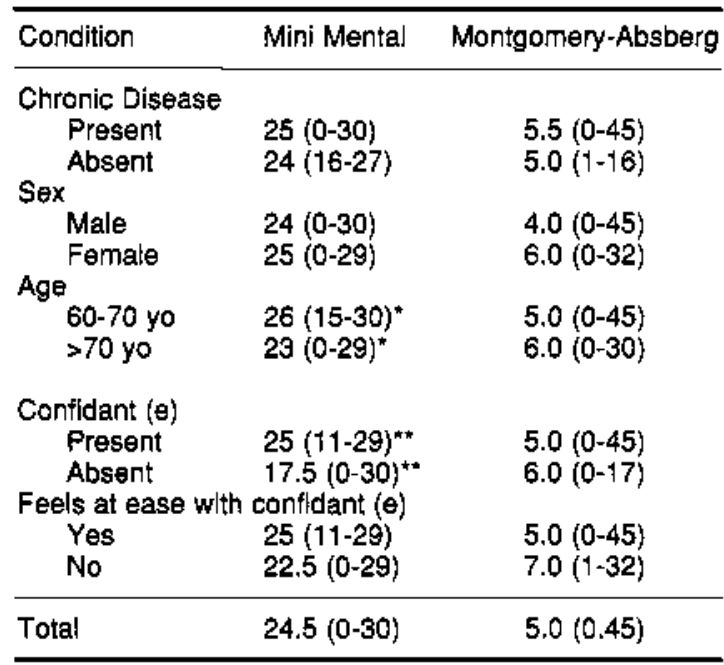

* $p=0.007$, Mann-Whitney U test

$* p=0.002$, Mann-Whitney U test

ease, and no statistical difference was found between the two groups. However, when diabetes mellitus and coronary disease were separated from other diseases and analysed together, depression scores were higher in the group with the risk factors (Mann-Whitney U test, $\mathrm{p}=0.0087$ ).

The presence of a confidant(e) was also analysed as a factor related to a subject's cognitive and depression performances. Mini Mental scores were significantly lower (Mann-Whitney U test) in the group which did not use this relationship of the socia: network ( $\mathrm{p}=0.0028$ ), although levels of symptoms of depression were not influenced by this variable.

The analysis of the variable "feels at ease with the confidant(e)" showed no differences of cognitive performance or levels of symptoms of depression as between subjects (Mann-Whitney U test, $\mathrm{p}>0.05$ ) (Table 3 ).

Age greater than 70 years old presented lower scores for the Mini Mental Exam (Table 4). This age effect was reported by the original Mini Mental work ${ }^{3}$ and has been demonstrated by many other studies ${ }^{41}$.

Correlation between age and scores of Mini Mental was significant only in the group with chronic diseases $(r=-0.51, p<0.001)$. When this analysis was carried out controlled by sex, only women presented this significant correlation $(\mathrm{r}=-0.51, \mathrm{p}<0.001)$. Correlations between age and Montgomery-Asberg scores were not significant either for the subgroups, or for the whole sample.
The evaluation of the independence to deal with the activities of daily living (moving, cooking, cleaning, personal hygiene and going out alone) was undertaken (Table 4). The most common problem reported by this sample was difficulty in going out alone $(19 \%)$, which showed a significant association only with cognitive deficit by univariate analysis (Mantael-Hanszel Chi-square, $\mathrm{p}=0.02$ ). When controlled by age, this association lost its statistical significance.

Other variables were also recorded in this survey, such as the use of medications and frequency of consultations during the previous month. Use of medication was reported by $80 \%$ of subjects, and $14 \%$ were using drugs which acted on the central nervous system. However, this did not influence Mini Mental performances as measured by the Mann-Whitney $U$ test $(p>0.05)$.

Half of the sample had seen a physician during the previous month, $34 \%$ of them at the Conceição Unit and $16 \%$ at other medical services.

Table 4 - Activities of Daily Living (number and proportion of abilities maintained.

\begin{tabular}{lcc}
\hline Varlable & Numbers of Subjects & $\%$ \\
\hline Moves around alone & 56 & 90 \\
Cooking and cleaning & 52 & 84 \\
Personal hygiene & 56 & 90 \\
Going out alone & 50 & 81 \\
\hline
\end{tabular}

\section{Dlscussion}

\section{Demographic Data}

The present sample was composed of $67 \%$ of women. This higher frequency of women may be explained by: 1 . the empirical hypothesis that it would be easier to find women at home; 2 . females enrol more frequently in health systems; and 3. they present a longer life span as compared to males.

The frequency of cognitive deficit was $29 \%$ and the detectable level of depressive symptoms was of $30 \%$. Both rates are high and a subject selection bias should be considered due to the small size of the sample. These rates could also be observed because individuals registered in health services may be those with more health problems, thus increasing the risk for cognitive problems and symptoms of depression. Another explanation may be provided by the fact that subjects who respond to the interview may be sicker and more likely to be found at home. In the study of Veras and Coutinho ${ }^{42}$ the prevalence of cognitive deficit was 
of $29.7 \%$ in the district of Santa Cruz. This higher rate, compared to the other two districts in the sample, was explained as a result of the lower educational and socioeconomic conditions of this group. In the present study, before any socio-economic hypothesis is raised to explain the results, the problems discussed above should be considered.

The use of screening tests, scales or questionnaires to detect subjective symptoms may introduce some problems. Although the Mini-Mental Exam has been validated for a Brazilian sample

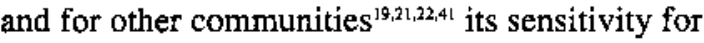
screening major cognitive disturbances was of $81 \%$ and it showed a false positive rate of $32 \%$, which could be responsible for misidentification. In order to obtain a definitive diagnosis a more complex, expensive and time-consuming evaluation is needed in order to reveal cases of dementia, cognitive deficit without dementia and false positives.

The Montgomery-Asberg scale also presents difficulties, since it has not been studied as a means of screening for detectable symptoms of depression in Brazilian sample communities. However, rating scales are of use chiefly in detecting the presence of symptoms rather than in assessing depression as a disorder quantitative$1 y^{7,31}$, and may be suitable for the discovery of cases, e.g., in epidemiological surveys ${ }^{7.28,36}$. The selection of screened cases is important for the application of a "gold standard" diagnostic evaluation to understand the real possibilities for its use.

The presence of cognitive deficit and depression is higher in populations exposed to various risk factors (lack of primary health care, high prevalence of risk factors for cerebrovascular disorders and cardiovascular diseases, nutritional disorders, early retirement and others $)^{27,39,43,44}$.

Retirement rate was $82 \%$ in the present survey, representing a high level of financial dependence on the family and loss of an active social role. Illiteracy rate was $13 \%$, however no differences were found between illiterates and literates in the number of subjects screened by the Mini-Mental Exam. It may reinforce the need for the adequate adjustment of the cutoff point for illiterates, although the probability of statistical error type $\Pi$ (beta) ${ }^{14}$ must be considered due to the small size of the present sample and the small number of illiterates $(n=9)$.

\section{Social Support and Network}

The existence of a confidant(e) was reported by $93 \%$ of subjects. In order to get social support individuals must have relationships with other people; however, this network does not guarantee access to social support ${ }^{34}$. One's social network may be seen, therefore, as the structure through which social support is provided, where social support is a measure of the functional content of social relationships and refers to resources or helpful functions provided for an individual by other persons ${ }^{10}$. This network can be further characterized by the structure of the relationships (e.g., "size", intensity, or frequency). Many studies have often confused measures of social network size with the general concept of social support and/or used the terms synonymously ${ }^{34}$. Therefore, the literature on social networks and their contribution to social support reflects multiple definitions, perspectives and outcomes ${ }^{38}$. The lack of comparability among studies and the reflection of multiple definitions could be the reason for the apparent conflict of results ${ }^{37}$.

Some investigators have found a lack of social support associated with a high risk of institutional admission, higher risk of disease and poorer mental health ${ }^{4.11}$. The present study is of cross-sectional design and is not able to identify direction of effect or causality of association between social variables and mental disease or cognitive deficit. However, it seems that an association between social (presence of persons to talk to: confidant(e)), health status (presence of risk factors for cerebrovascular disease) and cognitive performance/level of symptoms of depression is present, although the nature of the relationship is still not very clear.

\section{Chronic Disease}

No difference was observed in Mini-Mental scores between groups (with or without disease); however, the small size of the sample "without" disease would explain, at least in part, the results.

The presence of higher levels of depressive symptoms in the diabetes and/or heart disease group is to be explained by the fact that these diseases are risk factors for cerebrovascular disorders (i.e., multi-infarct dementia, among others), which may cause nore depressive symptoms than primary degenerative dementias (i.e., Alzheimer's dis-

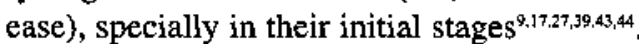

In a previous multicenter study about the health needs of the elderly population carried out in the District of S. Paulo ${ }^{32}$, the results showed a highly deprived population ( $70 \%$ presented a per capita income of less than US\$100 per month), 
living mostly in multi-generational households, with a high prevalence of chronic physical illness (only $14 \%$ declared no illness) and psychiatric disorders $(27 \%)$, and loss of autonomy $(47 \%)$. Those results are similar to the present ones, despite all the problems raised with regard to the size of the sample, and concern the need for specialized health services and social support for the growing population of elderly people in Brazil.

In conclusion, there is a need to undertake research into the present subject using larger and more representative samples. Tests and scales of easy application, such as Mini Mental and Montgomery-Asberg, should be used by profes-

\section{References}

1. ADI: Alzheimer's Disease International. Global Perspect., 1(2):3, 1990.

2. ALMEIDA FILHO, $\mathrm{N}$, et al. Estudo epidemiológico dos transtornos mentais em uma população de idosos: área urbana de Salvador-BA. J. Bras. Psiquiatr., 33:114-20, 1984.

3. BERKMAN, L. \& SYME, S. Social networks, host resistance and mortality; a nine-year followup study of Alameda County residents. Am.J. Epidemiol., 9:186-204, 1979.

4. BLAZER, D. Social support and mortality in an elderly community population. Am. J. Epidemiol., 115: 684-94, 1982.

5. BLAZER, D. \& WILLIAMS, C. Epidemiology of dysphoric and depression in an elderly population. Am.J. Psycbitr, 137: 439-44, 1980.

6. BLAY, S.L. et al. The use of the face-hand test to screen for organic brain syndromes: a pilot study, Rev. Saúde Püblica, 23:395-400, 1989.

7. CARROLL, B.J. et al. Depression rating scales. Arch. Gen. Psychiatr., 28: 361-6, 1973.

8. CENTRO INTERNACIONAL DE GERONTOLOGIA SOCIAL (CIGS). Curso de formación en gerontologia. Rio de Janeiro, 1990, p.30-1.

9. CHAVES, M.L.F \& IZQUIERDO, I. Differential diagnosis between dementia and depression: a study of efficiency increment. Acta Neurol. Scand, 85: 378-82, 1992.

10. COHEN, S. \& SYME, L. Social support and bealth. Orlando, Academic Press, 1985.

11. COHEN, M. et al. Client-related risk factors of nursing home entry among elderly adults. $J$. Gerontol., 41: 785-92, 1986.

12. DRATCU, L, et al. Depression assessment in Brazil. Br.J. Psycbiatr., 150: 797-800, 1987.

13. FEIJO, R.B. Repercussão da presença de doença orgânica e da suspeita de transtorno mental em adolescentes de 13 a 20 anos. Porto Alegre, 1994.[Dissertaçăo de Mestrado Universidade Federal do Rio Grande do Sul]. sionals of primary care to screen for cognitive deficit and signs and symptoms of depression among elderly people.

Their early identification by the primary health care system is necessary so that more adequate action for the community may be presented. Health planners should develop studies with a view to identifying major risk groups for depression and cognitive problems so as to augment their preventive action for the aged. A detailed analysis of the quality and structure of the social network of the population may offer important resources so that individuals may be kept in the community.

14. FLEISS, J.L. The design and analysis of clinical experiments. New York, Willey, 1986.

15. FOLSTEIN, M. et al. Mini-mental state: a practical method for measuring the cognitive state of patients for the clinician. J. Psycbiatric Res., 12: 189-98, 1975.

16. FUNDAÇÀO IBGE. Anuârio estatístico do Brasil. Rio de Janeiro, 1988.

17. HACHINSKI, V.C. et al. Cerebral blood flow in dementia. Arcb. Neurol., 32: 632-7, 1975.

18. HICKEY, T. Health and aging. Monterey, Brooks/Cole, 1980.

19. HOLZER, C.E. et al. An epidemiologic assessment of cognitive impairment in a community population. In: Greeney, J.R. Research in community mental bealth. London, JAI Press, 1984, p. 3-32.

20. JORM, A et al. Educational level differences on the Mini- mental state: the role of test bias. Psychol. Med., 18: 727-31, 1988.

21. JORM, A. et al. Performance of the informant questionnaire on cognitive decline in the elderly (IQCODE) as a screening test for dementia. Psychol. Med., 21: 785-90, 1991.

22. KAY, D.W.K. et al. Dementia and depression among the elderly lving in the Hobart community: the effect of the diagnostic criteria on the prevalence rates. Psycbol. Med., 15: 77188, 1985.

23. KEARNS, N.P. et al. A comparison of depression rating scales. Br. J. Psychiatr, 141: 45-9, 1982.

24. KIRSHNER, H. Bebavioral neurology: a practical approach. Edinburgh, Churchill Livingston, 1986.

25. MCDOWELL, I. \& NEWELL, C. Measuring bealtb: a guide to rating scales and questionnaires. New York, Oxford Lniversity Press, 1987.

26. MONTGOMERY, S.A. \& ASBERG, M. A new depression scale designed to be sensitive to change. Br, J. Psycbiatr, 134: 382-9, 1979.

27. MURREL, S.A. et al. Prevalence of depression and its correlates in older adults. $A m . J$. Epidemiol, 117: 173-85, 1983. 
28. NIEISEN, A. et al. Prevalence and recognition of depression among ambulatory patients in a group medical practice. Proceedings $A m$. Psycbiatr, Ass., 60: 17-31, 1972.

29. O'CONNOR, D.W. et al. The influence of education, social class and sex on Mini-mental state scores. Psychol. Med, 19: 771-6, 1989.

30. ORGANIZACION MUNDLAL DE LA SALUD Programa de Promoción de la Salud de los Ancianos. Genebra, 1990.

31. PRUSOFF, B.A. et al. Concordance between clinical assessment and patients' self-report in depression. Arch. Gen. Psycbiatr, 26: $546-$ 52, 1972 .

32. RAMOS, L.R. et al. Perfil do idoso em área metropolitana na regiào Sudeste do Brasil: resultados de inquérito domiciliar. Rev. Saúde Pública, 27: 87-94, 1993.

33. RAMOS, L.R. Growing old in São Paulo, Brazil: assessment of health status and social support of elderly people from different socio-economic strata living in the community. London, 1986. [PhD thesis - London School of Hygiene and Tropical Medicinel.

34. SEEMAN, T. \& BERKMAN, L. Structural characteristics of social networks and their relationship with social support in the elclerly: who provides support. Social Sci. Med, 26:737-49, 1988.

35. SHAPIRO, E. \& TATE, R. Who is really at risk of institutionalization? Gerontologist, 28: 237-45, 1988.
36. SNAITH, R.P. et al. Assessment of the severity of primary depressive illness. Wakefield selfassessment depression inventory, Psycbol. Med., 1: 143-9, 1971 .

37. STEIN, A. A cross-sectional study of social support and hypertension in Porto Alegre. London, 1990. [MSc. London School of Hygiene and Tropical Medicine].

38. STEINBACH, U. Social networks, institutionalization, and mortality among elderly people in the Lnited States. J. Gerontol, 47: \$183-90, 1992.

39. STERN, M.J. et al. Life adjustment postmyocardial infarction: determining predictive variables. Arch. Intern. Med., 137: 1680-5, 1977.

40. THOMAS, R.G. The elderly in a changing world. In: World Health Chronicle World Health Organization. Geneva, 1979, p.3-7.

41. TOMBAUGH, T. \& MCINTYRE, N,J, The minimental state examination: a comprehensive review. J. Am. Geriatr. Soc., 40: 922-35, 1992.

42. VERAS, R.P. \& COUTINHO, E. Prevalência da síndrome cerebral orgânica em população de idosos de área metropolitana da região Sudeste do Brasil. Rev. Saúde Pública, 28: 2637, 1994.

43. WELLS, K, B, et al. Psychiatric disorders in a sample of the general population with and without chronic medical conditions, $A m . J$. Psycbiatr., 145: 976-81, 1988.

44. WINOKUR, G. The concept of secondary depression and its relationship to comorbity. Psychiatr, Clin. Nonth Am., 13: 567-83, 1990.

\begin{abstract}
Resumo
Com o objetivo de avaliar déficit cognitivo e presença de sinais e sintomas depressivos, 62 idosos registrados numa Unidade de Saude Comunitária em Porto Alegre/RS toram entrevistados em suas casas. Foram avaliados pelo Mini Exame do Estado Mental (Mini Mental State), pela escala de Montgomery-Asberg, e por um questionário sobre condiçōes de saujde, moradia $\theta$ outras variáveis de vinculos sociais. Nivels mais altos de sintomas depressivos foram observados entre os idosos expostos a fatores de risco maiores para doença cérebro-vascular (diabete $\theta$ doença coronariana), enquanto que plor desempenho cognifivo fol encontrado nos sujeitos que nåo contavam com um confidente (variável da rede social). Os resultados sugeriram que a identificaçāo precoce dos grupos idosos de risco pode auxillar na prevenção de problemas sociais e de sacide, mantendo as indivíduos na comunidade.
\end{abstract}

Depressāo, epidemiologia. Transtornos cognitivos, epidemiologia. Idoso. 